\title{
The Double Star mission
}

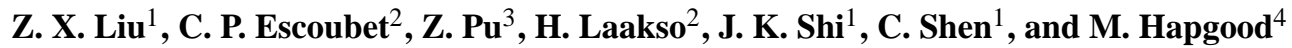 \\ ${ }^{1}$ CSSAR, Chinese Academy of Sciences, P.O. Box 8701, Zhong, 100080 Beijing, China \\ ${ }^{2}$ ESA/ESTEC, SCI-SH, Keplerlaan 1, 2200 AG Noordwijk, The Netherlands \\ ${ }^{3}$ Department of Geophysics, Peking University, Yiheyuan Street, \#5, 100871 Beijing, China \\ ${ }^{4}$ RAL, Chilton, Didcot, Oxon OX11 0QX, UK
}

Received: 17 February 2005 - Revised: 31 March 2005 - Accepted: 6 April 2005 - Published: 8 November 2005

Part of Special Issue "Double Star - First Results"

\begin{abstract}
The Double Star Programme (DSP) was first proposed by China in March, 1997 at the Fragrant Hill Workshop on Space Science, Beijing, organized by the Chinese Academy of Science. It is the first mission in collaboration between China and ESA. The mission is made of two spacecraft to investigate the magnetospheric global processes and their response to the interplanetary disturbances in conjunction with the Cluster mission. The first spacecraft, TC-1 (Tan Ce means "Explorer"), was launched on 29 December 2003, and the second one, TC-2, on 25 July 2004 on board two Chinese Long March 2C rockets. TC-1 was injected in an equatorial orbit of $570 \times 79000 \mathrm{~km}$ altitude with a $28^{\circ}$ inclination and TC-2 in a polar orbit of $560 \times 38000 \mathrm{~km}$ altitude. The orbits have been designed to complement the Cluster mission by maximizing the time when both Cluster and Double Star are in the same scientific regions. The two missions allow simultaneous observations of the Earth magnetosphere from six points in space. To facilitate the comparison of data, half of the Double Star payload is made of spare or duplicates of the Cluster instruments; the other half is made of Chinese instruments. The science operations are coordinated by the Chinese DSP Scientific Operations Centre (DSOC) in Beijing and the European Payload Operations Service (EPOS) at RAL, UK. The spacecraft and ground segment operations are performed by the DSP Operations and Management Centre (DOMC) and DSOC in China, using three ground station, in Beijing, Shanghai and Villafranca.
\end{abstract}

Keywords. Magnetospheric physics (Magnetopause, cusp, arid boundary layers; Magnetotail; General or miscellaneous)

\section{Introduction}

The history of scientific collaboration between China and ESA began in 1980 through the signing of a document that facilitates the exchange of information between ESA and the

Correspondence to: C. P. Escoubet

(philippe.escoubet@esa.int)
Commission for Science and Technology of China. Twelve years later, the Chinese approached ESA with a proposal to establish a Chinese Cluster Data and Research Centre in Beijing for the ESA Cluster mission (Escoubet et al., 1997, 2001)

China's request to participate in an international space programme culminated in an official cooperation agreement that was signed on 25 November 1993. As a result of this agreement, a number of Chinese scientists and engineers were hosted by ESA and the institutes of Cluster principal investigators (PIs), while five of their compatriots became coinvestigators on Cluster.

The next step happened in November 1997, when ESA visited the Center for Space Science and Applied Research (CSSAR) in Beijing to discuss the next collaboration between China and ESA. At the meeting CSSAR gave a presentation on the proposed Double Star Programme to the ESA delegation. The ESA delegation then expressed willingly to join in the Double Star Programme, and the minutes were signed by the two sides in Beijing.

In July 1998, CSSAR presented the concept of the Double Star programme at the Cluster Science Working Team meeting in ESTEC. Six Cluster PIs responded to the invitation to participate by offering the flight spare models of their Cluster experiments.

In September 1999, ESA was invited by the China National Space Administration (CNSA) to discuss ESA/China collaboration in space activities and particularly collaboration on the Double Star Programme. In March 2000, the Double Star Phase A report was presented to ESA and to the Cluster Science Working Team. Once again, the European response was very positive.

Further progress was made in December 2000, when Double Star was given the green light by the Chinese government. In April 2001, a European delegation composed of ESA representatives and European PIs visited CNSA in order to finalize the preparation of the agreement between the two agencies and to review the project's status. Finally, on 9 July 2001, an historic agreement to develop the joint 

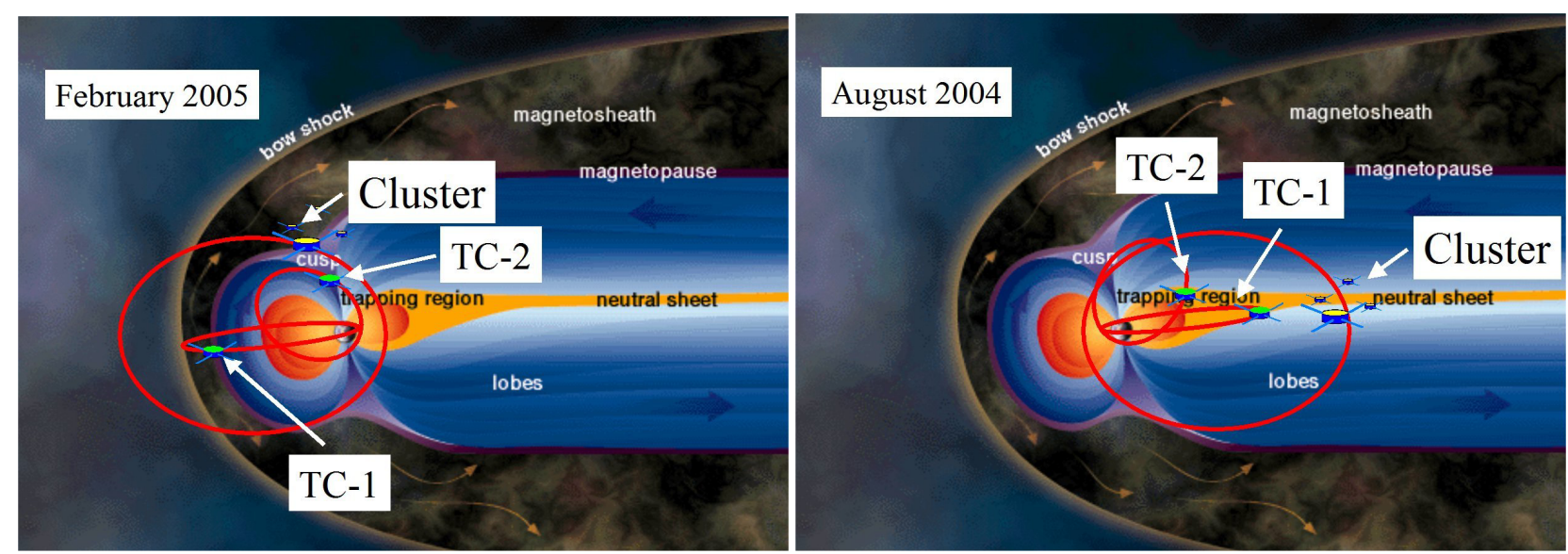

Fig. 1. Double Star and Cluster orbits during winter (left) and summer (right).

Table 1. TC-1 and TC-2 orbit information on 30 October 2004.

\begin{tabular}{llll}
\hline \multicolumn{2}{c}{ Equatorial Double Star (TC-1) } & \multicolumn{2}{c}{ Polar Double Star (TC-2) } \\
\hline Perigee altitude & $577 \mathrm{~km}$ & Perigee altitude & $558 \mathrm{~km}$ \\
Apogee altitude & $78916 \mathrm{~km}$ & Apogee altitude & $38362 \mathrm{~km}$ \\
Inclination & $28.25 \mathrm{deg}$. & Inclination & 89.88 \\
Period & $27.4 \mathrm{~h}$ & Period & $11.5 \mathrm{~h}$ \\
Spin period & $4.1 \mathrm{~s}$ & Spin period & $4.1 \mathrm{~s}$ \\
\hline
\end{tabular}

mission was signed at ESA Headquarters in Paris by ESA and CNSA.

Under the agreement, ESA agreed to contribute to the refurbishment and pre-integration of the eight European instruments, acquisition of data for $4 \mathrm{~h}$ per day and co-ordination of scientific operations. China's contribution includes the two spacecraft buses, eight scientific experiments, launch and operations.

\section{Scientific objectives}

The main goal of the Double Star mission is to study the effect of the Sun on the near-Earth environment. The scientific objectives of the mission are:

- to understand the transfer of solar wind plasma and energy through the various boundaries of the magnetosphere: the bow shock, the magnetopause, the polar cusp and the plasma sheet boundary layer,

- to study the magnetic reconnection process at the magnetopause and in the magnetotail,

- to study the acceleration of plasma at the magnetopause, in the magnetotail, and in the auroral zone,

- to understand the role of the small scale processes in the large scale plasma structures,
- to understand the substorm processes and locate the breakup point in the magnetotail,

- to study the geomagnetic storms and their effects on the magnetosphere and ionosphere.

To achieve these objectives, the Double Star spacecraft have been placed into two orbits complementary to the Cluster orbits (Table 1). The DSP orbits have been designed to maximize the number of simultaneous crossings of Cluster and DSP in the cusp and in the neutral sheet (Liu and RodriguezCanabal, 1998). In the late summer and early autumn, the satellites are studying the magnetotail structure and in particular the substorm phenomena. There Cluster is at about $19 \mathrm{R}_{E}$ down the tail, TC- 1 at $13.4 \mathrm{R}_{E}$ and TC-2 crossing the nightside auroral zone (Fig. 1, right panel). This configuration allows to study substorms and the location of the substorm breakup in the magnetotail. Cluster was designed to study the energy release mechanisms of substorms in the mid magnetotail region (e.g. Baker and McPheron, 1990). However, a few years ago, some scientists suggested that the substorms might be generated closer to the Earth (e.g. Lyons, 2000), in regions that can be best studied by Double Star. The joint mission enables both hypotheses to be tested simultaneously.

Six months later, during late winter and early spring, Cluster and Double Star TC-1 have the apogee in the solar wind and Double Star TC-2 is in the polar cusp (Fig. 1, left panel). Many conjunctions between the Cluster and Double Star can be found at the bow shock, the magnetopause and the polar cusp from January to March. For instance, about 40 conjunctions were predicted between January and April 2004 with Cluster within $\pm 2 \mathrm{~h}$ from the magnetopause and TC- 1 within $\pm 1 \mathrm{~h}$ (M. Hapgood, private communication). A special ISSI working group has been formed to study the conjunctions of Cluster and Double Star at the dayside magnetopause (Dunlop et al., 2005). 


\section{The spacecraft}

As its name suggests, Double Star involves two satellites - each designed, developed, launched and operated by the CNSA - flying in complementary orbits around the Earth. Both were launched by upgraded, three-stage Long March $2 \mathrm{C}$ rockets, but different launch sites were used to satisfy the two orbit inclinations required to fulfill the scientific objectives.

Each cylindrical satellite has a diameter of $2.1 \mathrm{~m}$, a height of $1.2 \mathrm{~m}$ and a mass of $340 \mathrm{~kg}$ and generates electrical power from solar cells that are exposed to sunlight as the spacecraft spins on its axis. The two spacecraft structures are identical and only the communication booms are different: TC-1 carries one communication boom on top of the spacecraft (long tripode visible on Fig. 2) and TC-2 has two booms, one at the top and one at the bottom. In addition two deployable $3.5 \mathrm{~m}$ booms, attached at the bottom of the spacecraft, carry the fluxgate and search coil magnetometers. The spin axis is perpendicular to the ecliptic and the spacecraft makes 15 rotations per minutes (same as Cluster) enabling the full three-dimensional particle distribution functions to be measured every $4 \mathrm{~s}$.

Special attention has been taken for magnetic cleanliness and a dedicated programme, including tests in a magnetic cleanliness facility, was conducted to minimize the effect of spacecraft interferences. Unfortunately, after the launch of TC-1 it was found that a spurious magnetic field was produced by the solar panels. The consequence is a complicated calibration process to produce high resolution magnetometer data (Carr et al., 2005). On the other hand, spin resolution data are produced routinely but care must be taken in the analysis. In addition, also on TC-1, the solid boom carrying the search coil instrument (STAFF) did not deploy. Rather good wave measurement can still be made when the waves are strong (lion roars or chorus) or when the spacecraft is in eclipse (Cornilleau et al., this issue). These problems were corrected on TC- 2 by changing the position of the cables on the back of the solar panel and the type of pyros in the boom deployment system.

\section{Instruments}

Each Double Star spacecraft carries eight scientific instruments (Table 2). The instruments are measuring dc and ac magnetic fields, distribution functions of electron and ions of low and high energies, and energetic neutral atoms. In addition a spacecraft potential control is included on TC-1 to keep the spacecraft close to the plasma potential.

The key aspect of Europe's participation in Double Star was the inclusion of seven instruments identical to those flying on the Cluster spacecraft. The new NUADU experiment was developed by a joint program of the National University of Ireland, CSSAR (China) and IRF (Sweden). The other eight experiments were provided by Chinese institutes.

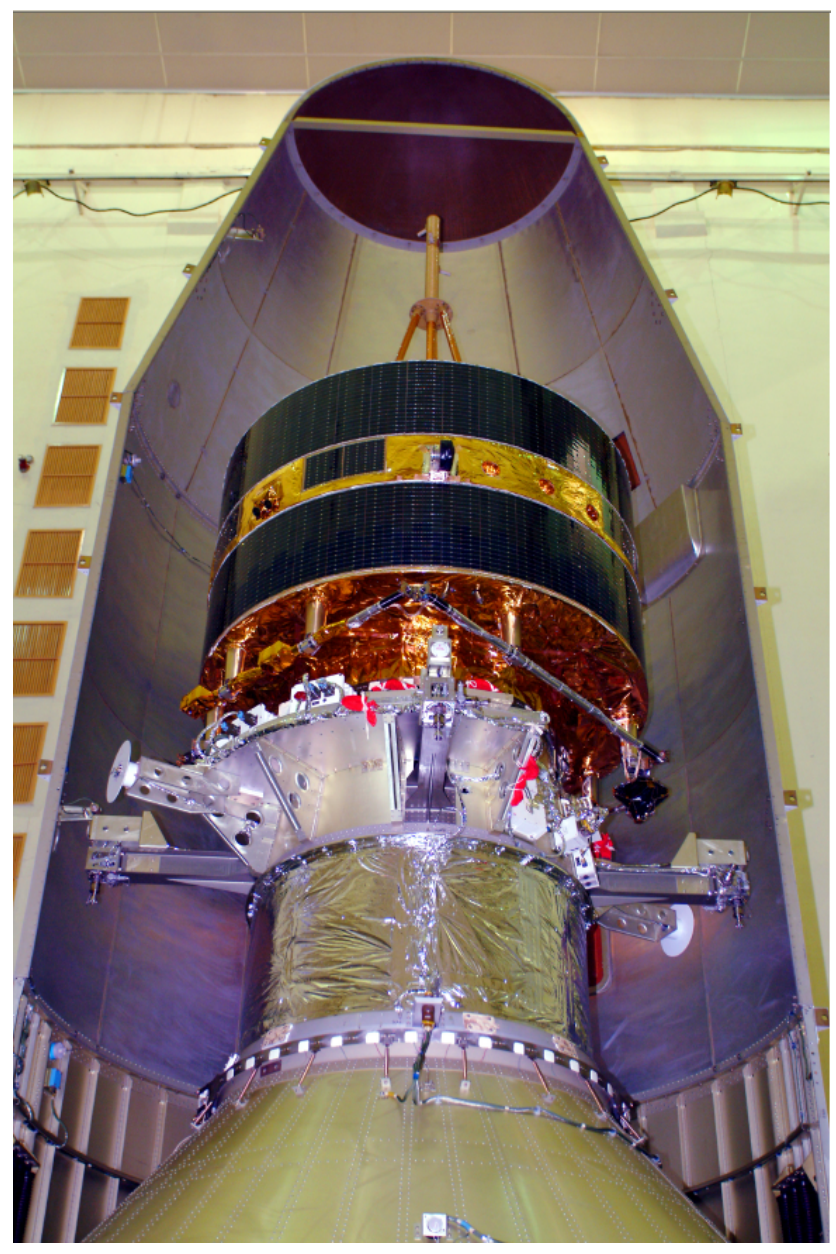

Fig. 2. Double Star TC-2 spacecraft before encapsulation in the Long March fairing. Underneath the spacecraft, the solid upper stage with the attitude control system was specifically developed for the mission.

The fact that most of the European science payload was derived from Cluster "spares" made it possible to prepare and launch them quickly on Double Star during the operational lifetime of ESA's quartet.

The bit rate of each spacecraft is $15 \mathrm{kbit} / \mathrm{s}$ and the telemetry is shared as shown on Table 3. The particle instrument (PEACE and HIA) have more telemetry per sensor than on Cluster, which allow to transmit 3-D distribution functions every spin (PEACE) or every few spins (HIA).

\section{Science operation and science data system}

CNSA and ESA have set up the DSP Operation and Data Management System (DODMS), which mainly includes the DSP Operation and Management Center (DOMC) in Beijing, the DSP Science Applied System (DSAS) at the CSSAR in Beijing, and the European Payload Operation Service (EPOS) at Rutherford Appleton Laboratory in UK. The main task of the DODMS is to manage and coordinate the science 
Table 2. Double Star scientific payload.

\begin{tabular}{|c|c|c|c|}
\hline \multicolumn{2}{|c|}{ Equatorial Double Star (TC-1) } & \multicolumn{2}{|c|}{ Polar Double Star (TC-2) } \\
\hline Instruments & PI & Instruments & PI \\
\hline $\begin{array}{l}\text { Active Spacecraft Potential Control (ASPOC) } \\
\text { indium ions } 50 \mu \mathrm{A} \max \end{array}$ & $\begin{array}{l}\text { K. Torkar, IWF, } \\
\text { Graz, Austria }\end{array}$ & $\begin{array}{l}\text { Neutral Atom Imager (NUADU) } \\
45 \mathrm{KeV}<\text { Eena }<300 \mathrm{KeV}\end{array}$ & $\begin{array}{l}\text { S. McKenna-Lawlor, } \\
\text { Ireland U., Ireland; } \\
\text { L. Lu, CSSAR, China; } \\
\text { S. Barabash, IRF, Sweden }\end{array}$ \\
\hline Fluxgate Magnetometer (FGM) , 22 vector/s & C. Carr IC, UK & Fluxgate Magnetometer (FGM) 22 vector/s & T. Zhang, IWF, Austria \\
\hline Plasma Electron and Current Exp. (PEACE) & A. Fazakerley, MSSL, & Plasma Electron and Current Exp. (PEACE) ) & A. Fazakerley, MSSL, \\
\hline$\# 1 \mathrm{eV}<\mathrm{Ee}<25 \mathrm{KeV}$ & Dorking, UK & $\# 1 \mathrm{eV}<\mathrm{Ee}<25 \mathrm{KeV}$ & Dorking, UK \\
\hline Hot Ion Analyzer (HIA), sensor 2 of CIS ) & H. Reme, CESR, & Low Energy Ion Detector (LEID) & Q. Ren and J. B. Cao, \\
\hline $5 \mathrm{eV}<\mathrm{Ee}<32 \mathrm{KeV}$ & Toulouse, France & $* 50 \mathrm{eV}<\mathrm{Ee}<25 \mathrm{KeV}$ & CSSAR, China \\
\hline $\begin{array}{l}\text { Part of Spatio-Temporal Analysis } \\
\text { of Field Fluct.(STAFF) }\end{array}$ & $\begin{array}{l}\text { N. Cornilleau/H. Alleyne, } \\
\text { CETP, Velizy, France }\end{array}$ & $\begin{array}{l}\text { Low Frequency Electromagnetic } \\
\text { Wave detector* (LFEW) }\end{array}$ & $\begin{array}{l}\text { Z. Wang and J. B. Cao, } \\
\text { CSSAR, China }\end{array}$ \\
\hline $0<\mathrm{f}<4 \mathrm{kHz}+$ Digital Wave processor (DWP) & and Sheffield, U., UK & $8 \mathrm{~Hz}<\mathrm{f}<10 \mathrm{kHz}$ & \\
\hline $\begin{array}{l}\text { High Energy Electron Detector (HEED)* } \\
0.2<\mathrm{Ee}<10 \mathrm{MeV}\end{array}$ & $\begin{array}{l}\text { W. Zhang and J. B. Cao, } \\
\text { CSSAR, China }\end{array}$ & $\begin{array}{l}\text { High Energy Electron Detector (HEED)* } \\
0.2<\mathrm{Ee}<10 \mathrm{MeV}\end{array}$ & $\begin{array}{l}\text { W. Zhang and J. B. Cao, } \\
\text { CSSAR, China }\end{array}$ \\
\hline $\begin{array}{l}\text { High Energy Proton Detector (HEPD)* } \\
3<\mathrm{Ep}<400 \mathrm{MeV}\end{array}$ & $\begin{array}{l}\text { J. Liang and J. B. Cao, } \\
\text { CSSAR, China }\end{array}$ & $\begin{array}{l}\text { High Energy Proton Detector (HEPD)* } \\
3<\mathrm{Ep}<400 \mathrm{MeV}\end{array}$ & $\begin{array}{l}\text { J. Liang and J. B. Cao, } \\
\text { CSSAR, China }\end{array}$ \\
\hline $\begin{array}{l}\text { Heavy ion detector (HID)* } \\
10 \mathrm{MeV}<\mathrm{Ei}<8 \mathrm{GeV}\end{array}$ & $\begin{array}{l}\text { Y. Zhai and J. B. Cao, } \\
\text { CSSAR, China }\end{array}$ & $\begin{array}{l}\text { Heavy ion detector (HID)* } \\
10 \mathrm{MeV}<\mathrm{Ei}<8 \mathrm{GeV}\end{array}$ & $\begin{array}{l}\text { Y. Zhai and J. B. Cao, } \\
\text { CSSAR, China }\end{array}$ \\
\hline
\end{tabular}

* Instrument built by China

\# PEACE includes only one sensor on each spacecraft

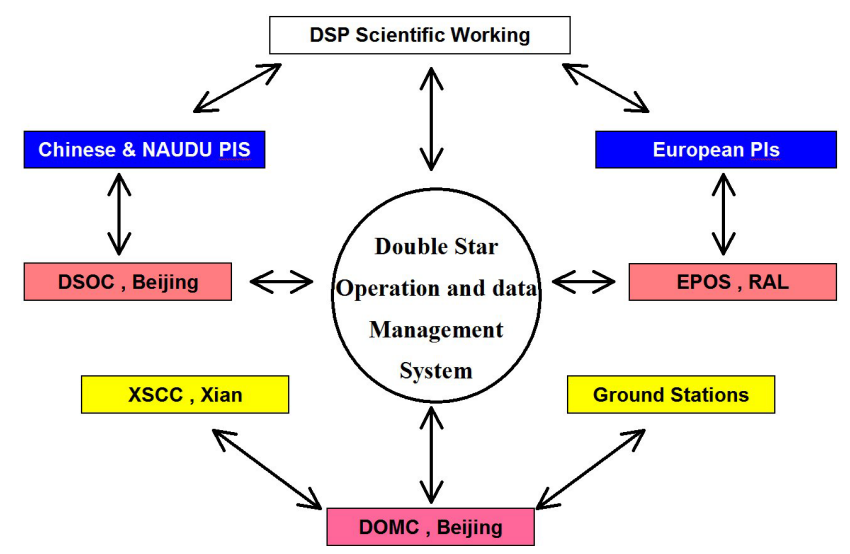

Fig. 3. The Double Star Science Operation System.

operation system and science data system of the DSP mission.

\subsection{Science operations}

The science operations are mainly carried out by the coordination of DSP Science Operation Center (DSOC) at the CSSAR, the DSP Operation and Management Center (DOMC) in Beijing and the European Payload Operation Service (EPOS) at Rutherford Appleton Laboratory in UK.

Figure 3 illustrates the Double Star Science Operation System. DSP Science Operation Center (DSOC) is responsible, in collaboration with the DSP science working team, for the production of the Master Scientific Operation Plan (MSOP) (Shen et al., 2005), which include the operation schedules of the 16 scientific instruments, the modes and timelines of the
Table 3. Main characteristics of the Double Star instruments.

\begin{tabular}{cccc}
\hline Instruments & Mass $(\mathrm{kg})$ & Power $(\mathrm{W})$ & Data rate $(\mathrm{bps})$ \\
\hline ASPOC-TC1 & 2.54 & 2.9 & 108 \\
FGM-TC1/TC2 & 3.1 & 3.6 & 1211 \\
HEED-TC1/TC2 & 2.2 & 2.0 & 224 \\
HEPD-TC1/TC2 & 2.2 & 2.0 & 202 \\
HID-TC1/TC2 & 2.2 & 2.0 & 45 \\
HIA-TC1 & 3.5 & 2.8 & 4440 \\
LEID-TC2 & 4.0 & 4.0 & 2000 \\
LFEW-TC2 & 4.0 & 5.0 & 3000 \\
NUADU-TC2 & 5.7 & 4.6 & 4224 \\
PEACE-TC1/TC-2 & 6.5 & $3.8-4.8$ & 4624 \\
STAFF/DWP-TC1 & 4.9 & 4.0 & 3509 \\
\hline
\end{tabular}

Payload Service System (PSS) on both satellites, and also the schedules of the three ground stations. The production of MSOP is based on the main scientific objectives of DSP, S/C orbits, S/C resources, S/C visibility from the ground stations, space environment and conjunctions between the two DSP satellites and Cluster. EPOS is coordinating the scientific operations of the European payload in the planningcommanding processes. DOMC checks the commands of the payload, generate bit streams and send them to Xian Satellite Control Center (XSCC) for up-linking to S/C and execution.

\subsection{Double Star science data system}

Data from the Double Star experiments are relayed to the Chinese DSP Science and Application System (DSAS) in Beijing by DSP Operation Management Center (DOMC) 
Table 4. Selected guest investigators.

\begin{tabular}{|c|c|}
\hline Guest investigator & Investigation \\
\hline D. Boscher, Onera, Toulouse, F & Radiation Environment Research from Multiple Monitors using Double Star \\
\hline S. Buchert, IRF-U, S & $\begin{array}{l}\text { Magnetosphere-ionosphere coupling, field-aligned currents and ion flow near } \\
\text { the dayside cusp and auroral zone using ground-based, Double Star and Cluster }\end{array}$ \\
\hline M. Dunlop, RAL, UK & Co-ordinated Cluster-DSP measurements in the cusp and at the magnetopause \\
\hline J. Jahn, SWRI, USA & Multi-Spacecraft Energetic Neutral Atom Observations of Magnetospheric Processes \\
\hline F. Pitout, ESTEC, NL & Double Cusps and Reconnection Hypotheses \\
\hline T. Pulkkinen, FMI, Finland & Global Understanding of Storms in the Inner Magnetosphere \\
\hline S. Schwartz, QMW, UK & Kinetic Processes and Conditioning in the Dayside \\
\hline (now at: Imperial College, UK) & Magnetosheath and Equatorial Geomagnetic Tail \\
\hline J. Wild, Leicester U., UK & $\begin{array}{l}\text { A coordinated in-situ and remote-sensing investigation of magnetosphere-ionosphere } \\
\text { coupling exploiting Double Star, Cluster and ground-based experiments }\end{array}$ \\
\hline
\end{tabular}

which collects the telemetry data via the ESA ground station at Villafranca (Spain) and the Chinese ground stations in Beijing and Shanghai. A dedicated network line has been set up between Villafranca and Beijing to facilitate the transfer of data. The European Space Operations Centre (ESOC) is in charge of the operations of the Villafranca ground station, while CSSAR is in charge of the operations of the Beijing and Shanghai ground stations.

Once the telemetry data have been decompressed, they are sent to DSAS that generates the DSP raw data files (i.e. the DSP level 1 data files) according to the DSP data delivery interface document. Then the raw data become available for the Chinese instrument groups, and at the same time, they are also sent to the European DSP Data Disposition System, colocated with the Austrian DSP Data Center in Graz, where the data files are made available for the European PIs. Next, the Chinese DSP Data Center with help of Chinese instrument groups processes the data and produces the standard DSP data products for Chinese instruments (Fig. 4). The three European DSP data centers (Austrian, French and UK ) with help of European PIs process the raw data to produce the standard DSP data products and send them to the other data centres, with an exception that the NUADU data processing is executed in Beijing. After that, Chinese DSP Data Center will exchange the standard DSP data products with the Austrian DSP Data Center that distributes them to the European scientists.

During some orbits we have to reduce the data acquisition intervals to avoid overwriting data on the solid state recorder. The reduction was done regularly on TC-1 in 2004 but much less often in 2005. The Master Science Operations Plan defines the data acquisition of TC-1 and TC-2 (Shen et al., 2005).

In addition to its role in planning-commanding, EPOS has also developed the DSP Data Management System (DDMS) that distributes data to the scientific users, and the Double Star QuickLook web page (DSDS web) that displays the latest data from both European and Chinese instruments. The DSDS web is hosted by the

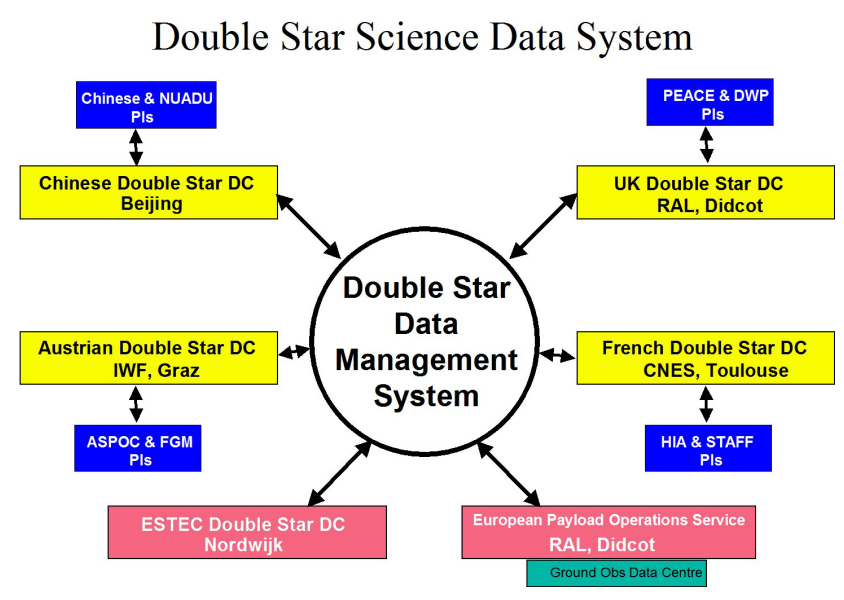

Fig. 4. The Double Star Science Data System.

Austrian data centre. More information on the Double Star data system and the physical parameters available can be found at http://www.rssd.esa.int/index.php?project= DOUBLESTAR\&page=data_ring and ftp://ftp.estec.esa.nl/ pub/csds/task_for/users_guide/dsdsguide.html.

\section{Guest investigator programme}

To enhance the scientific return from the double star mission, the first announcement of opportunity to select guest investigators for the Double Star mission was issued in June 2003. Eight proposals were proposed and all were selected (see Table 4), covering various aspects of magnetospheric physics and co-ordinating Double Star and Cluster measurements. Most of them are based on data analysis, except one, on storms and the inner magnetosphere, that combined data with theory/simulations. 


\section{Conclusions}

The Double Star mission consists of two spacecraft to study the Sun-Earth connection in tandem with the Cluster mission. For the first time, six-point measurements of the main plasma parameters are performed in the key scientific regions of the near-Earth environment. The coupling between the smallscale processes and the evolution of large-scale structures can be investigated. This joint mission will prepare for the future multi-point missions that will be necessary to understand and later on, be able to predict the effects of the Sun and solar wind on the Earth environment.

The collaboration between ESA, the European institutes and China was also a human adventure since it was the first time that European hardware was flown on a Chinese built spacecraft. Many ups and downs were encountered from the initial discussions in 1997 to the second launch in 2004 but the highly motivated scientists and engineers from both sides made this mission possible.

The nominal mission ended in July 2005. CNSA and ESA Science Committees agreed to extend the mission up to July 2006 for TC-2 and end 2006 for TC-1.

Acknowledgements. We gratefully acknowledge the ESA Director of Science D. Southwood, the CNSA former Administrator L. Enje and the actual CNSA Administrator S. L. Yan, the ESA Project Manager B. Gramkow, the CSSAR Director W. Ji, the CAST Project Manager Y. Shigeng, the ESA data co-ordinator G. Kreiner, the ESOC co-ordinator E. Soerensen, the CSSAR instrument co-ordinator H. Zhao, the CSSAR PI C. Jin-Bin, the DSP orbit Manager L. Qiang, the EPOS Project Manager R. Stamper, the JSOC Project Manager T. Dimbylow, the EDDS Manager G. Laky, the QMW data structure Manager T. Allen, the CESR data products Manager I. Dandouras and all European PIs: H. Alleyne, C. Carr, N. Cornilleau-Wehrlin, A. Fazakerley, S. McKennaLawlor, H. Reme, K. Torkar, T. Zhang. Finally we would like to thank R. Bonnet, ESA Science Director when the Double Star project was kicked-off, who was always convinced that collaboration with China on Double Star would be a success.

Topical Editor T. Pulkkinen thanks J. M. Bosqued and S. J. Schwartz for their help in evaluating this paper.

\section{References}

Baker, D. N. and McPherron, R. L.: Extreme energetic particle decreases near geostationary orbit, J. Geophys. Res., 95, 6591, 1990.

Carr, C. , Brown, P., Zhang, T. L., Gloag, J., Horbury, T., Lucek, E., Magnes, W., O’Brien, H., Oddy, T., Auster, U., Austin, P., Aydogar, O., Balogh, A., Baumjohann, W., Beek, T., Eichelberger, H., Fornacon, K.-H., Georgescu, E., Glassmeier, K.-H., Ludlam, M., Nakamura, R., and Richter, I.: The Double Star magnetic field investigation: instrument design, performance and highlights of the first year's observations, Ann. Geophys., 23, 27132732, 2005.

Cornilleau-Wehrlin, N., Alleyne, H. S. C., Yearby, K. H., de la Porte de Vaux, B., Santolik, O., Parrot, M., Belmont, G., Rezeau, L., Le Contel, O., Roux, A., Attié, D., Robert, P., Bouzid, V., Herment, D., and Cao, J.-B: The STAFF-DWP wave instrument on the DSP equatorial spacecraft: description and first results, Ann. Geophys., 23, 2785-2801, 2005.

Dunlop, M. W., Taylor, M. G. G., Davies, J. A., Owen, C. J., Pitout, F., Fazakerley, A. N., Pu, Z., Laakso, H., Bogdanova, Y. V., Zong, Q.-G., Shen, C., Nykyri, K., Lavraud, B., Milan, S. E., Phan, T. D., Rème, H., Escoubet, C. P., Carr, C. M., Cargill, P., Lockwood, M., and Sonnerup, B.: Coordinated Cluster/Double Star observations of dayside reconnection signatures, Ann. Geophys., 23, 2867-2875, 2005.

Escoubet, C. P., Russell, C. T., and Schmidt, R. (Eds.): The Cluster and Phoenix missions, Space Sci. Rev., Vol 79, Nos. 1-2, 1997.

Escoubet, C. P., Fehringer, M., and Goldstein, M.: The Cluster mission, Ann. Geophys., 19, 1197, 2001,

SRef-ID: 1432-0576/ag/2001-19-1197.

Liu, Q. and Rodriguez-Canabal, J.: A preliminary study on collaborative geomagnetic measurements between Cluster II and Double Star Program, ESA/ESOC internal document, 1998.

Lyons, L. R.: Determinations of relative timing of near-Earth substorm onset and tail reconnection, ESA SP-443, p. 255, 2000.

Shen, C. and Liu, Z.-X.: Double Star project - master science operations plan, Ann. Geophys., 23, 2851-2859, 2005. 